\title{
Evaluation OF MECHANICAL PROPERTY ON PALM/COIR BASED POLYMER MATRIX COMPOSITES
}

\author{
Pradeep, P. ${ }^{1}$ and Edwin Raja Dhas, J. ${ }^{2}$ \\ ${ }^{1}$ Department of Mechanical Engineering, Noorul Islam University, Kumaracoil, Tamil \\ Nadu, India \\ ${ }^{2}$ Department of Automobile Engineering, Noorul Islam University, Kumaracoil, Tamil \\ Nadu, India
}

\section{$A B S T R A C T$}

Now day's natural fibres as reinforcement have received more attention from the research community all over the world in preparing polymer composites. These natural fibres have lot of advantages over synthetic fibres. In this paper two natural fibers palm and coir reinforced composites were fabricated using compression moulding method which was a new effort and was not done elsewhere. Specimens were cut from the fabricated composite plates according to the ASTM standards. Universal Testing Machine was used for testing tensile and flexural strength of the composites. The impact strength of the composites was analyzed using Impact tester. Further wear and moisture absorption tests were also conducted on the prepared specimen. The results obtained through experimentation of both composites were compared and presented. It can be concluded that the developed palm based composite possess superior property and can be recommended for fabrication of light weight high strength automobile parts.

\section{KEYWORDS}

Natural fiber, palm, coir, mechanical properties

\section{INTRODUCTION}

Composite materials are man made material with origin during Old Stone Age. Use of eco friendly composites gains attraction in the recent years due to its lightweight and moderate strength. Due to increased awareness on the part of end users and pressure from legislators, the composite industry has begun investigating the possibility of increasing the proportion of recycled or biodegradable composite materials. Accordingly, efforts were being deployed to find alternative reinforcement and resin systems that are environmentally friendly while providing the same performance as their synthetic counterparts. Natural fibers offer the potential to act as a reinforcing material for low to medium strength applications such as automotive, sporting goods, marine, electrical, industrial, construction, household appliances, etc. Natural fibers are available in abundance in nature and can be used to reinforce polymers to obtain light and strong materials. Natural fibers from plants are beginning to find their way into commercial applications such as automotive industries, household applications, etc. [1]. Natural fibers have received much attention from the research community over the past decade. Natural fibers are now considered as a serious alternative to glass fibers for use in composite materials as reinforcing agents. The advantages of natural fibers over glass fibers are their low cost, low density, high strength-to-weight ratio, resistance to breakage during processing, low energy content and recyclability [2, 3]. Natural fibres have little resistance towards the environmental influences. This can be recognized in the composites and can be advantageously utilized for the development of biological degradable composites with good mechanical properties. The properties of the natural fiber based composites can be affected or modified by number of reasons like fiber combinations, processing of composites, etc. The process parameters and their influences on the properties are different with different 
combinations of fiber and matrix. Palmyra fiber is a natural fiber obtained from the leaf stalk and leaf stalk base of Palmyra tree (Borassus flabellifer), which is found in abundance in the southern parts of India. These fibers can be used as reinforcement in polyester matrix. Because of their lignocellulosic and organic origin, Palmyra fibres exhibit a hydrophilic nature. To achieve the full potential of polymer composites, they must have a good environmental stability. Moisture absorption in polymer composites and its effect on mechanical properties such as tensile, flexural and impact strength are reported by few scientists. In the field of technical utilization of plant fibers, banana fiber-reinforced composites represent one of the most important areas. Considering in particular banana, it is a well known fact that it is one of the oldest cultivated plants in the world. The word "banana" comes from Arabic and means "finger". It belongs to the Musaceae family, and there are approximately 300 species, but only 20 varieties are used for consumption. Approximately 40 million metric tons of bananas are produced every year by the tropical and subtropical regions of the world. In India approximately 1.5 million acres of land is cultivated with banana plantations, which yield about $3 \times 105$ tons of fibre. It has been noted that banana fibre has been substituted for asbestos in bitumen and can be used for roofing; also banana fibre/polymer composites and cotton fabric/polyester have been used in cars and for bearings, respectively. Banana fibre was the chosen material, due to its abundance and relative cheapness. The objective of this paper is to study the tensile, flexural, impact wear and moisture absorption properties of pseudostem banana fiber and palmya composites.

\section{LITERATURE REVIEW}

A number of investigations have been conducted on several types of natural fibers such as kenaf, hemp, flax, bamboo and jute to study the effect of these fibers on the mechanical properties of composite materials $[4,5]$. It was studied bamboo-mesh reinforced cement composites, this reinforcing material increase significantly its tensile, flexural, and impact strengths. Jute fabricreinforced polyester composites were compared with wood composite [6] and it was found that the jute fiber composite has better strengths [7]. The flexural properties of Agenta Pinnata fiber reinforced Epoxy composites was discussed [8]. The tensile properties of bamboo based polymer composites were studied [9]. The addition of sisal fiber content in high impact polystyrene improved stiffness and the tensile strength decreases [10]. Many natural fibers like jute, sisal, hemp, coir and banana have been tried to form a composite [11].Composites having two or more fillers contained in the same matrix are called as hybrid composites [12]. Sreekala et.al [13] reported hybridization of glass fiber with oil palm fiber reinforced composites improved the mechanical strength. The hybridization of fly ash in glass fiber epoxy on compressive and impact properties studied [14]. The sisal and oil palm hybrid composites reinforced natural rubber composites were studied [15]. Banana/Sisal hybrid composites enhanced the tensile and flexural properties [16] The Mechanical properties of glass/palmyra fiber waste sandwich composites enhance the mechanical strength due to hybridization [17]. The optimum content of banana fiber is $40 \%$ in polyester based composites [18]. Banana and glass hybrid fiber with varying fiber length and fiber content were tested [19]. Efforts have been made by many authors to evaluate the mechanical properties of Palmyra/glass fiber hybrid composites [20], banana empty fruit bunch fibre reinforced polyester composites [21], sisal-jute-glass fiber reinforced polyester composites [22], glass fiber- sisal/jute reinforced epoxy composites [23], jute and banana fiber reinforced epoxy hybrid composites [24] Palmyra Palm Leaf Stalk Fiber/jute fiber reinforced hybrid polyester composites [25]. The analysis of tensile, flexural, and impact properties [26] of these composites revealed that composites with good strength could be successfully developed using banana fiber as the reinforcing agent. 


\section{EXPERIMENTATION}

\subsection{Preparation of composites}

Polymer composites in form of plates were fabricated on pure polyester resin with alkali treated natural fibers as reinforcements under random orientation. For experimentation two set of plates were prepared, one plate with palm fruit fibers and other with coir fibers as reinforcements. The composite plates were made by conventional compression moulding Technique. After that these composites were cut using a saw cutter to get the required dimension as per ASTMD specimen standard for testing polymer composites.

\subsection{Tensile Testing}

The tensile test specimens were prepared according to ASTMD 638. For testing the specimen was mounted in the grips of the Instron universal tester with $10 \mathrm{~mm}$ gauge length. The stress strain curves $\mathrm{w}$ plotted during the test for the determination of ultimate tensile strength and elastic modulus. From the stress-strain curve, a straight line was drawn and from the slope of the line the Young's modulus or elastic modulus was determined. Average of two tests results was taken.

\subsection{Flexural Test}

The flexural test specimens were prepared according to ASTM D 790. Flexural properties were measured by conducting the three point bend test on computerized UTM using special attachment. The speed of test was set as $2 \mathrm{~mm} / \mathrm{min}$ at room temperature.

\subsection{Impact Test}

Impact test specimens were prepared according to ASTM D 6110. The specimen was clamped into the pendulum impact test fixture with the notched side facing the striking edge of the pendulum. The energy loss was obtained from reading at scale plate. The fracture values were calculated by dividing the energy absorbed by cross sectional area of the specimen

\subsection{Wear Test}

Wear test was performed by applying a constant load of $0.5 \mathrm{~N}$ on the prepared specimen against a rotating abrasive wheel. The weight losses of the specimen at four constant time intervals of 90 seconds were observed.

\subsection{Moisture Absorption Test}

Moisture Absorption Test was done by immersing the specimen in distilled water under continuous monitoring. After regular intervals of time the weight of the specimen was measured, thereby the amount of water absorbed was calculated.

\section{RESULTS AND DISCUSSION}

\subsection{Tensile Properties}

Figure 1 shows the percentage elongation of palm based composite and the coir based composite and the results reveal that the palm fiber composite elongated more.

Figure 2 shows the ultimate tensile strength (UTS) of palm based composite and the coir based composite. The ultimate tensile stress of palm based composite is greater than coir based composite. 
It was evident from the results of tensile test that the palm reinforced polyester composite possesses appreciable tensile values.

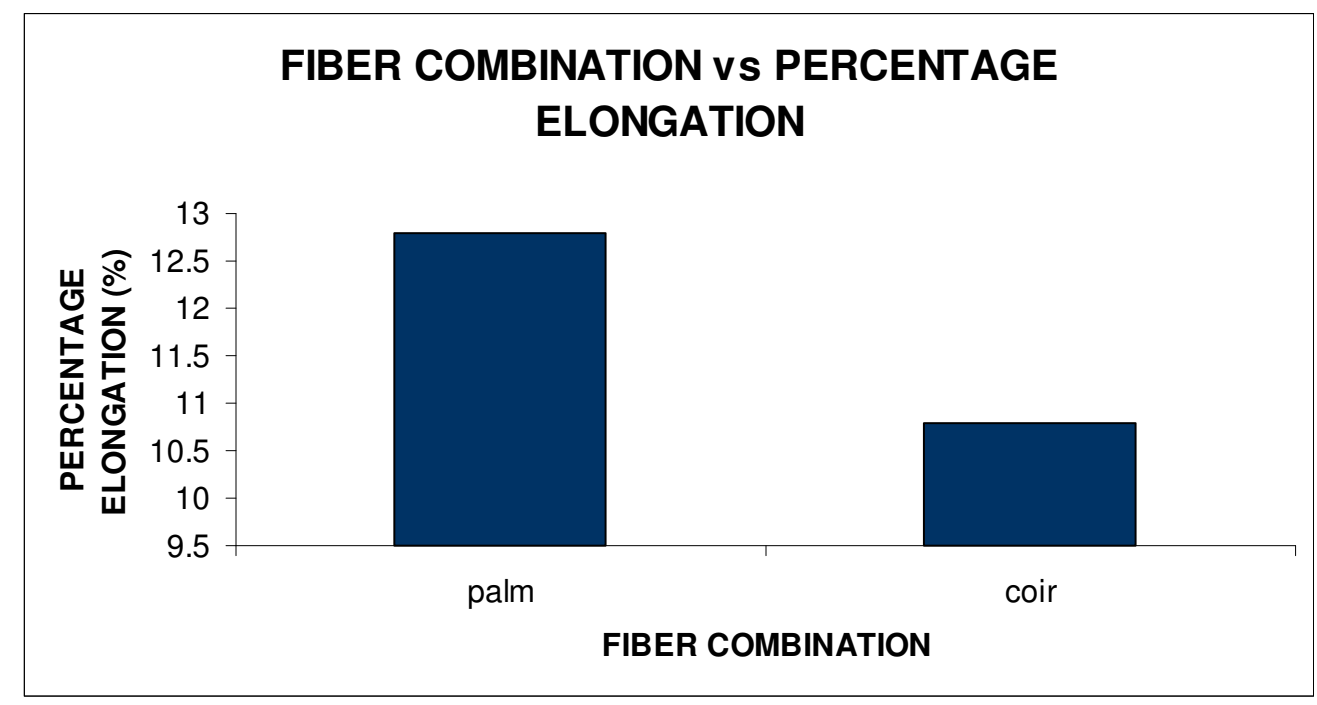

Figure 1 Comparison of effect of fiber combination on percentage elongation

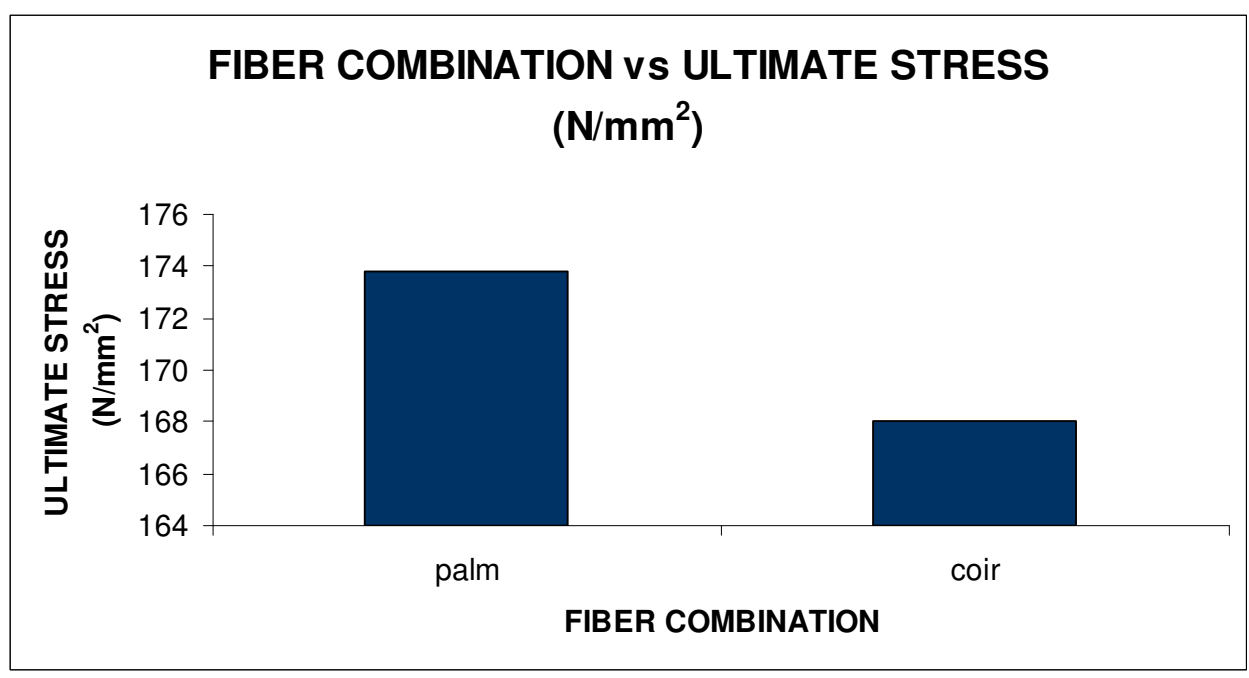

Figure 2 Comparison of effect of fiber combination on ultimate stress.

\subsection{Flexural Properties}

Figures 3 shows the flexural strength of palm based composite and the coir based composite. From the results of flexural test, the palm matrix composite shows better flexural property than coir matrix composite. 


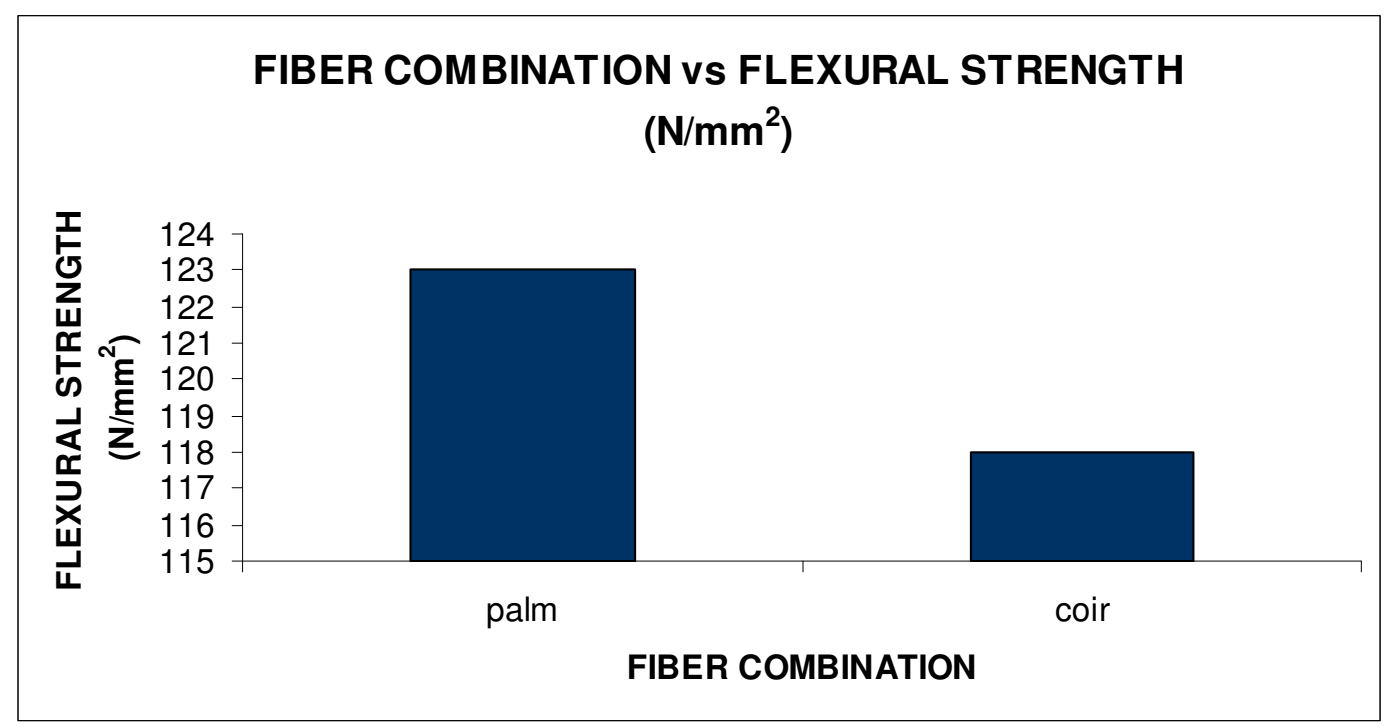

Figure 3 Comparison of effect of fiber combination on flexural strength.

\subsection{Impact Properties}

The impact responses of both composites were presented in Figure 4. The Palm based composite posses higher impact strength that leads to the higher toughness in the material.

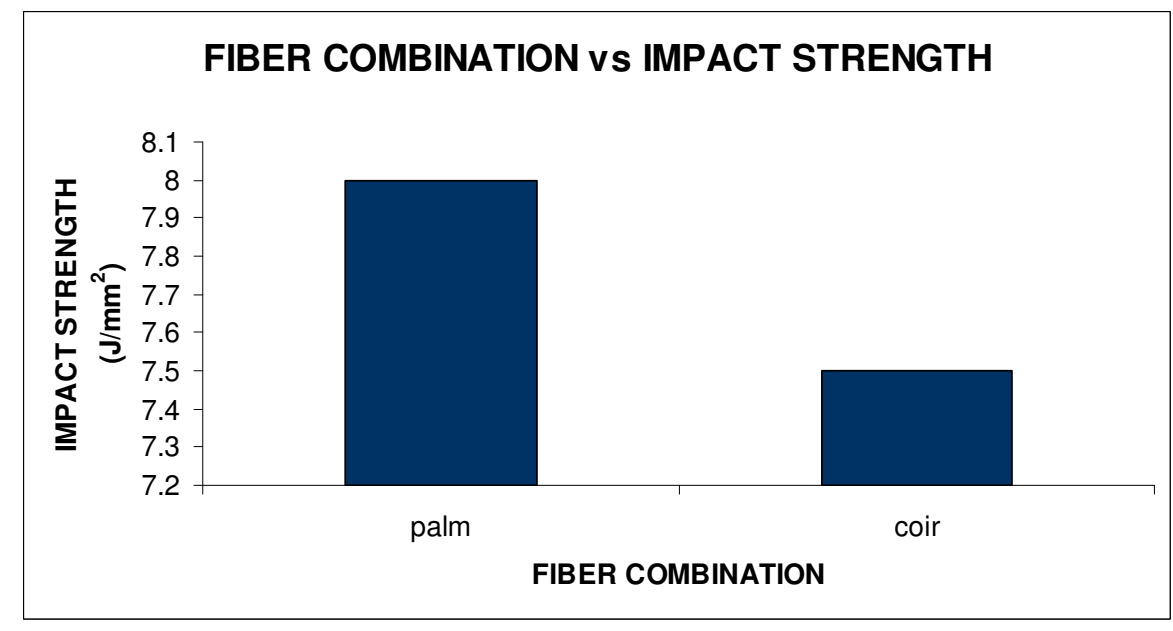

Figure 4 Comparison of effect of fiber combination on Impact length.

\subsection{Wear Properties}

Figure 5 represents the effect of fiber combination on the weight loss of the specimen. It was observed that palm specimen holding superior wear resistance on comparison with coir specimen. Also the weight loss on coir based composite was higher than palm based composites. 


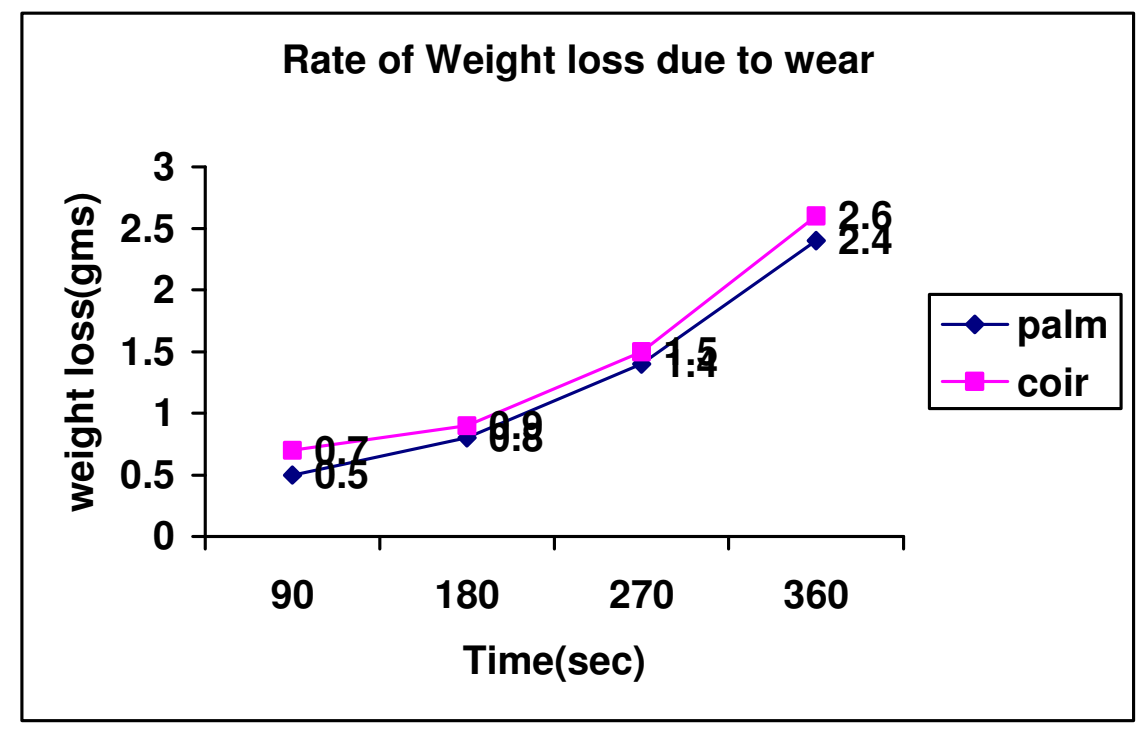

Figure 5 Comparison of effect of fiber combination on rate of weight loss due to wear.

\subsection{Moisture absorption Test}

Figure 6 shows the comparison of rate of absorption of moisture content between the two composites. It was observed that Palm fiber composites absorbed less moisture on comparing with coir fiber composites and holds a better result that they can be used in areas where the requirement is dry.

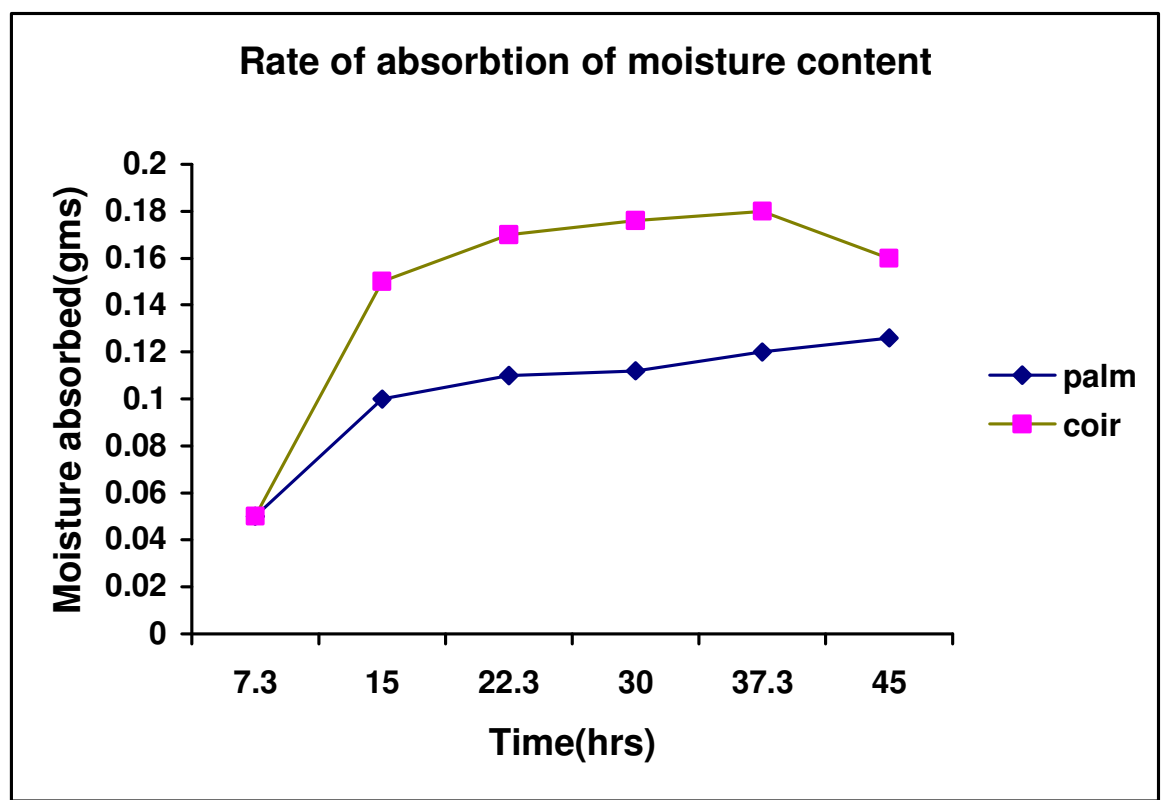

Figure 6 Comparison of effect of fiber combination on rate of absorption of moisture content. 


\section{Conclusion}

The effects of fiber combinations (palm fiber and coir fiber) with polyester resin on mechanical properties like tensile strength, flexural strength, impact strength, wear resistance and water absorption behaviour were studied. The various tests revel that the palm fiber based composite was superior to those of coir fiber based composite. Hence the palm fiber based composite shall be recommended for fabrication of automobile components with low cost, light weight and with high strength.

\section{REFERENCES}

[1] Wallenberger, F. T. \& Weston, N. (2004) Natural. Fibers, Plastics and Composites Natural,. Materials Source Book from C.H.I.P.S. Texas

[2] Bledzki, AK. Gassan.( 1999), J Composite reinforced with cellulose base fibers, Progr Polym Sci; 24, 224-74.

[3] Bolton, J. (1995). The Potential of Plant Fibres as Crops for Industrial Use. Outlook Agric, 24, 8589.

[4] Satyanarayana, K. G., K. Sukumaran, P. S. Mukherjee, C. Pavithran and S. G. K. Pillai. (1990), Natural Fiber-Polymer Composites, J. Cement and Concrete Composites, 12(2) pp. 117-136.

[5] Satyanarayana, K.G., Sukumaran, K. Kulkarni, A.G., Pillai, S.G.K. andRohatgi, P.K. (1986). Fabrication and Properties of Natural Fiber-reinforced Polyester Composites , Composties , 17: 329-333

[6] Mansur, M.A. and Aziz, M.A. (1983). Study of Bamboo-mesh Reinforced Cement Composites, The International Journal of Cement Composites and Lightweight Concrete , 5(3): 165-171

[7] Gowda, T. M. Naidu, A. C. B. Chhaya, R. (1999) Some Mechanical Properties of Untreated Jute Fabric-Reinforced Polyester Composites, Journal of Composites Part A: Applied Science and Manufacturing, 30(3), pp. 277-284.

[8] Sastra, H, Siregar, J, Sapuan, S and Hamdan, M (2006),'Tensile properties of Arenga pinnata fiberreinforced epoxy composites, Polymer-Plastics Technology and Engineering, vol. 45, no. 1, pp. 149155

[9] Kazuya Okubo, Toru Fujii, \& Yuzo Yamamoto. (2004). Development of bamboo-based polymer composites and their mechanical properties, Composites Part A: Applied Science and Manufacturing, 35 (3), 2004, 377-383.

[10] Antich, A. Vázquez, I. Mondragon and C. Bernal (2006). Mechanical behavior of high impact polystyrene rein forced with short sisal fibers, Composites Part A, 37, 2006, 139-150.

[11] Thi-Thu-Loan Doan, Shang-Lin Gao, Edith Mäder (2006). Jute/polypropylene composites I. Effect of matrixodification Composites Science and Technology, 66, 7-8, 952-963

[12] Colom, X., Carrasco, F., Pages, P. and Canavate, J. (2003). Effects of Different Treatments on the Interface of HDPE/Lignocellulosic Fiber Composites Compos Science and Technology; 63, 161-9.

[13] Sreekala, Jayamol George, Kumaran, M. G. Sabu Thomas,(2002) The mechanical performance of hybrid phenol-formaldehyde-based composites reinforced with glass and oil palm fibres, Composites Science and Technology, 623,339-353

[14] N Gupta, B. S Brar Woldesenbet, (2001) Effect of filler addition on the compressive and impactfiber reinforced epoxies. Bulletin of Materials Science, Vol. 24. 2, 219-223.

[15] Valadez, GA Cervantes, U Olayo, R Herrera-Franco, P.(1999) Chemical modification of hene-quen fibers with an organosilane coupling agent. Composites B; 30, 321-31.

[16] Jensena, R.E., Palmeseb, G.R. Mcknighta,. S.H.(2006). Viscoelastic properties of alkoxy silaneepoxy interpenetrating networks. Int. J. Adh. Adhes; 26(1-2), 103-15.

[17] Herrera-Franco A. Valadez-Gonza'lez, (2005) A study of the mechanical properties of short naturalfiber reinforced composites, Composites: Part B, 68, 597-608

[18] Laly A.Pothana, Zachariah Oommenb, Sabu Thomas,(2003) Dynamic Mechanical Composites , Composites Science and Technology, 63(2), pp. 283-293

[19] Joseph, S. Sreekala, M. S. Oommen, Z. Koshy, P. Sabu, T. (2002). A Comparison of the Mechanical Properties of Phenol Formaldehyde Composites Reinforced with Banana Fibers and Glass Fibers", Composites Science andTechnology, 62(14), pp. 1857-1868. 
[20] Velmurugan, R. Manikandan V. (2007) Mechanical properties of palmyra/glass fiber hybrid composites, Composites Part A: Applied Science and Manufacturing, Volume 38, Issue 10, Pages 22162226.

[21] Prasad, G Ratna Rao, A V Mohana Nagasrinivasulu, K(2009) Mechanical properties of banana empty fruit bunch fibre reinforced polyester composites IJFTR Vol.34(2) 162-167.

[22] Ramesh, M. Palanikumar, K. Hemachandra Reddy K. (2013).Mechanical property evaluation of sisal-jute-glass fiber reinforced polyester composites, Composites Part B: Engineering, Volume 48, Pages 1-9.

[23] Ramesh, M. Palanikumar, K. Hemachandra Reddy K. (2013).Comparative Evaluation on Properties of Hybrid Glass Fiber- Sisal/Jute Reinforced Epoxy Composites Procedia Engineering, Volume 51, Pages 745-750.

[24] Boopalan, M. Niranjanaa, M. Umapathy M.J. (2013).Study on the mechanical properties and thermal properties of jute and banana fiber reinforced epoxy hybrid composites Composites Part B: Engineering Volume 51, Pages 54-57.

[25] Shanmugam, D. Thiruchitrambalam M. (2013).Static and dynamic mechanical properties of alkali treated unidirectional continuous Palmyra Palm Leaf Stalk Fiber/jute fiber reinforced hybrid polyester composites, Materials \& Design, Volume 50, Pages 533-542.

[26] Sunder Kelkar, Pravin Kadam, Shashank Mhaske and Prakash Mahanwar. (2014). Toughening of Poly(Lactic Acid) By Ethylene-Co-Vinyl Acetate Copolymer Having Vinyl Acetate Content Of 18\%: Effect Of Ethylene-Co-Vinyl Acetate Content,Advances in Materials Science and Engineering;An International Journal (MSEJ), Vol. 1, pages 27-37.

\section{Authors}

P.Pradeep is currently pursuing his Ph.D. in Mechanical Engineering Department; Noorul Islam University - Thuckalay. He started his teaching career since 2006 onwards.

Dr. J. Edwin Raja Dhas was the H.O.D. of Automobile Engineering Department; Noorul Islam University -Thuckalay. He started his teaching career since 2005 onwards. 